\title{
Sistema reprodutivo e diversidade genética de quatro espécies de Myrciaria (Myrtaceae, jabuticabeiras)
}

\author{
Regina Célia Freitas Vilela ${ }^{1,3}$, José Geraldo de Aquino Assis ${ }^{1}$, Lamartine Nóbrega Filho² e Blandina Felipe Viana ${ }^{1}$
}

Recebido em 4/07/2011. Aceito em 20/04/2012

\section{RESUMO}

(Sistema reprodutivo e diversidade genética de quatro espécies de Myrciaria (Myrtaceae, jabuticabeiras)). A jabuticabeira é uma planta nativa da América do Sul e tem sofrido grande erosão genética devido à expansão da agricultura e desmatamento. Neste trabalho buscou-se investigar: a) o sistema reprodutivo de quatro espécies de Myrciaria spp. (Myrciaria cauliflora, M. jaboticaba, M. coronata e M. trunciflora); b) a compatibilidade de cruzamentos, utilizando tratamentos de polinização cruzada interespecíficos entre M. trunciflora x M. cauliflora e M. jaboticaba x M. coronata visando identificação de possíveis mecanismos de isolamento reprodutivos pós-zigóticos e c) relacionar a distância genética destas espécies e outros 14 táxons conservados ex situ, através de marcadores moleculares tipo RAPD. Os tratamentos reprodutivos mostraram que as jabuticabeiras são espécies autocompatíveis e não se observa apomixia. Os cruzamentos bidirecionais de polinização entre M. trunciflora x M. cauliflora e entre M. jaboticaba x M. coronata, produziram taxa de obtenção de frutos de 22 a $27 \%$ cujas sementes produziram plântulas normais evidenciando a falta de barreiras genéticas entre as espécies testadas, além de frutos abortados precocemente. Esta compatibilidade de intercruzamentos pode ser explorada no melhoramento genético, visando a transferência de caracteres de interesse em genótipos agronomicamente superiores. Foi encontrada pouca diferenciação genética entre os diferentes táxons, sugerindo que a similaridade genética observada não é compatível com a similaridade morfológica e os principais caracteres de valor taxonômico são polimórficos dentro do gênero.

Palavras-chave: compatibilidade, isolamento reprodutivo, jabuticaba, RAPD

\begin{abstract}
(Reproductive system and genetic diversity of four species of Myrciaria (Myrtaceae, jabuticabeiras)). The jabuticaba tree is a native plant from South America and has undergone genetic erosion due to agricultural expansion and deforestation. The present study aimed to investigate: a) the reproductive system of four species of Myrciaria spp. (Myrciaria cauliflora, M. jaboticaba, M. coronata and M. trunciflora); b) the compatibility of cross breeding using interspecific cross-pollination treatments between M. trunciflora x M. cauliflora and M. jaboticaba $\mathrm{x}$ M. coronata in order to identify possible postzygotic reproductive isolation mechanisms, and c) relate the genetic distance of these species and 14 other taxa preserved ex situ, by RAPD molecular markers. The reproductive treatments showed that jaboticaba are self-compatible species and no apomixis was found in these species. The bi-directional cross-pollinations between M. trunciflora x M. cauliflora, and between M. jaboticaba x M. coronata, generated fruit production that ranged from 22 to $27 \%$, and their seeds produced healthy plants, demonstrating the lack of genetic barriers between these species, as well as immature fruit dropping. Such compatibility of interbreeding can be explored in genetic improvements aimed at the transfer of traits of interest in agronomically superior genotypes. A low degree of genetic differentiation was found among the different taxa, suggesting that the genetic similarity observed is not compatible with the morphological similarity and the main taxonomic characters are polymorphic within the genus.
\end{abstract}

Key words: compatibility, reproductive isolation, jaboticaba, RAPD

\footnotetext{
${ }^{1}$ Universidade Federal da Bahia, Salvador, BA, Brasil

${ }^{2}$ Universidade Federal de Lavras, Lavras, MG, Brasil

${ }^{3}$ Autor para correspondência: reginacfv@hotmail.com
} 


\section{Introdução}

As jabuticabeiras pertencem à família Myrtaceae e ao gênero Myrciaria. A família Myrtaceae destaca-se como uma das famílias com maior riqueza de espécies na maioria das formações vegetacionais do Brasil (Romagnolo \& Souza 2004) e compreende cerca de 100 gêneros e 3.500 espécies de árvores, que se distribuem principalmente nas regiões tropicais e subtropicais do mundo (Barroso 1991; Marchiori \& Sobral 1997). A jabuticabeira é uma planta nativa da América do Sul (Morton 1987) e tem sofrido grande erosão genética devido à expansão da agricultura e desmatamento. Algumas espécies encontram-se restritas a coleções e correm o risco de extinção, pois possuem ocorrência limitada a áreas sujeitas ao desmatamento (Donadio 2000). Lorenzi et al. (2006) nos alertam para o plantio quase exclusivo de determinadas cultivares mais produtivas em detrimento de outras e observam a valiosa contribuição de colecionadores de frutíferas para a preservação de nossos recursos genéticos.

O sistema reprodutivo das plantas é resultado de características reprodutivas próprias e, também, de suas interações com o ambiente (Dafni et al. 2005). A família Myrtaceae é uma das famílias de maior importância no Brasil (Landrum e Kawasaki 1997) e, apesar disso, poucas espécies desta família têm sido estudadas quanto ao sistema reprodutivo. Sendo assim, é importante conhecer os mecanismos reprodutivos das espécies de jabuticabeiras e como estes mecanismos se refletem na diferenciação genética entre as diferentes espécies. Entre os trabalhos já publicados sobre o tema, podemos destacar o realizado no cerrado brasileiro sobre a biologia reprodutiva de oito Myrtaceae neotropicais, no qual foram descritos diversos aspectos da biologia reprodutiva das espécies (Proença \& Gibbs 1994) e o trabalho sobre a biologia floral e fenologia reprodutiva de Myrciaria dubia (camu-camu) no Pará, frutífera nativa da Amazônia (Maués \& Couturier 2002). Em estudo realizado sobre sistema de autoincompatibilidade presente em Acca sellowiana (Myrtaceae), foi sugerido haver um sistema de autoincompatibilidade tardia ou pós-zigótica para os acessos estudados (Santos et al. 2007).

A aplicação da genética nos estudos de conservação visa o entendimento da estrutura genética das populações e, para tanto, são necessárias informações básicas sobre a biologia reprodutiva da espécie investigada. Os marcadores moleculares têm sido frequentemente utilizados em estudos sobre diversidade e estrutura genética populacional (Zucchi 2002). Estes dados, associados a dados geográficos e ecológicos, têm permitido estabelecer relações de grande valor para a manutenção de bancos de germoplasma, tanto ex situ como in situ (Cansian 2003), para os trabalhos de melhoramento genético e ainda para a compreensão dos mecanismos de especiação.

Neste trabalho foi investigado o sistema reprodutivo de Myrciaria cauliflora (Mart.) O. Berg, M. jaboticaba (Vell.) O. Berg, M. coronata Mattos e M. trunciflora O. Berg; a compati- bilidade de cruzamentos interespecíficos entre $M$. trunciflora $\mathrm{x}$ M. cauliflora e M. jaboticaba x M. coronata visando identificação de possíveis mecanismos de isolamento reprodutivos pós-zigóticos; e identificação das estratégias das diferentes espécies para manutenção de sua integridade taxonômica. Além disso, o trabalho buscou identificar o grau de distância genética entre 66 plantas de jabuticabeiras de uma coleção ex $s i t u$, através de marcadores moleculares tipo RAPD.

\section{Material e métodos}

O trabalho foi realizado entre março de 2008 e fevereiro de 2009, em coleção ex situ de jabuticabeiras de aproximadamente 40 anos, na região do Sul de Minas Gerais, Brasil (45⒉' $58^{\prime \prime}$ W de longitude, $21^{\circ} 14^{\prime} 74^{\prime \prime} \mathrm{S}$ de latitude e $817 \mathrm{~m}$ de altitude). Esta coleção conta com 71 plantas e possui exemplares de 18 táxons de jabuticabeiras, originários de vários estados brasileiros. O clima da região é do tipo Cwa, segundo a classificação de Köppen, definido como subtropi$\mathrm{cal}$, com inverno seco e verão úmido. Registra temperatura média anual de $19,4^{\circ} \mathrm{C}$ e precipitação anual em torno de $1.500 \mathrm{~mm}$ (Brasil, 1992).

\section{Tratamentos de polinização}

Para os estudos do sistema reprodutivo, foram utilizadas de 3 a 6 plantas de cada espécie, selecionadas devido à ocorrência de floração. Foram realizados os seguintes tratamentos, que foram acompanhados até a maturação dos frutos ou abscisão das flores: (1) apomixia - botões florais foram emasculados no dia anterior à antese, ensacados e deixados sem manipulação; (2) autopolinização espontânea - flores ensacadas e mantidas sem manipulação; (3) autopolinização manual - flores foram ensacadas no dia anterior à antese e, após a abertura das flores, se realizou a polinização manual com grãos de pólen de flores do mesmo indivíduo; (4) controle ou polinização aberta - botões florais foram marcados e deixados acessíveis aos visitantes florais. Os cruzamentos interespecíficos foram feitos entre M. trunciflora $\times$ M. cauliflora e M. jaboticaba x M. coronata, por essas apresentarem sobreposição no período de floração.

Em todos os tratamentos foram utilizados copos plásticos pequenos, individuais para ensacar cada flor. Estes copos foram vedados com fita crepe ao redor do tronco, identificados e acompanhados até o desenvolvimento dos frutos. Os tratamentos de polinização foram realizados no período da manhã devido à maior oferta de pólen. As sementes resultantes destes cruzamentos foram colocadas para germinar individualmente em sacos para mudas, sob sombrite e em substrato contendo terra $(60 \%)$ e composto orgânico (40\%).

\section{Análise Genética}

A análise genética foi realizada em 66 das 71 plantas da coleção, que incluem 18 diferentes táxons dos quais são reconhecidas pelo menos cinco espécies, utilizando-se 
marcadores genéticos de DNA tipo RAPD (Williams et al. 1990). Uma amostra de jambeiro vermelho [Syzygium malaccense (L.) Merr. \& L. M. Perry - Myrtaceae] foi utilizada como grupo externo (Tab. 1). O método de extração utilizado foi o CTAB (Lodhi et al. 1994) com modificações, conforme Costa (2003).

Após a padronização do DNA, para cada reação de PCR foram utilizados 2,25 $\mu \mathrm{l}$ de DNA (10ng.ml) e 9,76 $\mu \mathrm{l}$ do mix $(4,49 \mu \mathrm{l}$ de água bidestilada; $1,0 \mu \mathrm{l}$ de tampão; $0,66 \mu \mathrm{l}$ de dNTP (mistura equitativa de dATP, dGTP, dCTP e dTTP); 2,25 $\mu \mathrm{l}(0,4 \mathrm{mM})$ de primer; $0,96 \mu \mathrm{l}$ de Taq diluente e $0,4 \mu \mathrm{l}$ de Taq DNA polimerase), obtendo-se 12,01 $\mu$ de volume final. Foram utilizados 12 primers de 10 bases de sequência arbitrária (AL 01, AL03, AL 04, AL 05, AL 07, AL 10, AL 15, AL 16, AL 20, AX 05, AX 06, AX 17), desenvolvidos pela Operon Tecnologies. As reações de amplificação foram realizadas em termociclador Eppendorf MasterCycler Gradient 5331. O programa de amplificação consistiu de uma denaturação inicial do DNA a $94^{\circ} \mathrm{C}$ por 2 min, seguido de 39 ciclos que incluem 15 seg a $94^{\circ} \mathrm{C}$ (denaturação), 30 seg a $35^{\circ} \mathrm{C}$ (anelamento), 1 min a $72^{\circ} \mathrm{C}$ (polimerização) seguido de um ciclo de 7 min a $72^{\circ} \mathrm{C}$ e finalmente uma estabilização a $10^{\circ} \mathrm{C}$. Os fragmentos amplificados foram separados em gel de agarose a 1,4\%, com eletroforese em tampão TBE $1 \mathrm{X}$ a uma voltagem de $100 \mathrm{v}$ por aproximadamente 2,5h. Após este período o gel foi corado com brometo de etídio e visualizado sob luz ultravioleta Fotodyne. O resultado foi documentado através de fotodocumentador EDAS 290 (Kodak ${ }^{\circledR}$ ).

Com os dados obtidos foi montada uma matriz binária, onde as bandas polimórficas foram analisadas quanto a sua ausência ou presença. Os dados foram transferidos para o programa Excel e analisados através do software Past versão 1.81 (Hammer et al. 2001). Foi obtida uma matriz de similaridade genética, utilizando o Coeficiente de Similaridade de Jaccard a partir do qual foi obtido dendrograma a partir do método de UPGMA.

\section{Resultados e discussão}

\section{Experimentos de polinização}

Os testes de autopolinização espontânea realizados nas quatro espécies produziram frutos normais, ou seja, plenamente formados e desenvolvidos, resultado que sugere que as jabuticabeiras podem ser plantas autocompatíveis. As jabuticabeiras não produzem frutos por apomixia em nenhuma das espécies testadas, ou seja, não houve formação de frutos e sementes sem fecundação (Tab. 2).

O tratamento com flores abertas a visitação obteve $44 \%$, $32 \%$ e $38 \%$ de frutos produzidos para as espécies Myrciaria jaboticaba, M. trunciflora e M. cauliflora, respectivamente, enquanto que a autopolinização espontânea obteve pegamento de 17\%, 8\% e 9\% para as espécies Myrciaria coronata, M. trunciflora e M. cauliflora respectivamente (Tab. 2). Somente em M. jaboticaba, a porcentagem de polinização das flores abertas à visitação foi equivalente à autopolinização espontânea. Não foi possível obter resultado da polinização aberta em M. coronata, devido ao insucesso do tratamento.

Este incremento da produtividade em $M$. trunciflora e M. cauliflora observado nos experimentos de polinização com flores abertas à visitação, evidencia a importância dos polinizadores para esta cultura. Jabuticabeiras isoladas com produção normal de frutos são comuns em pomares domésticos, porém, segundo Morton (1987), as jabuticabeiras isoladas são menos produtivas do que quando plantadas em grupos, indicando que a polinização cruzada incrementa a produção de frutos. Isto fica evidenciado, quando comparamos os resultados dos experimentos de polinização espontânea e polinização aberta (controle).

A autopolinização é uma estratégia eficaz para garantir o sucesso da polinização e, também, uma grande vantagem em locais com deficiência de polinizadores (Bawa 1974). O número de espécies da subfamília Myrtoideae que são autocompatíveis assemelha-se ao das espécies que são incompatíveis (Lughadha \& Proença 1996). Aproximadamente $20 \%$ das plantas superiores são predominantemente autocompatíveis, sendo que a polinização cruzada ocasional nestas espécies possui consequências importantes (Kearns \& Inouye 1993), como incremento da produção e manutenção da variabilidade genética.

Nos experimentos de autopolinização manual, Myrciaria coronata obteve resultado de $33 \%$ de produção de frutos. Para as outras espécies o resultado obtido foi nulo provavelmente, devido a erro na execução dos tratamentos.

Os cruzamentos bidirecionais de polinização interespecífica entre M. trunciflora $\times$ M. cauliflora e entre M. jabotica$b a \times M$. coronata, apresentaram formação de frutos normais e frutos pequenos e mal formados. Ocorreu variação entre 22 a $27 \%$ de formação de frutos normais (Tab. 3).

Esta taxa é considerável, quando comparada à taxa de produção de frutos da polinização aberta, que não ultrapassou $44 \%$. Em todos os estes cruzamentos houve formação de frutos, com uma ou mais sementes, não fugindo ao normalmente encontrado nos frutos destas espécies. As sementes foram colocadas para germinar logo após a colheita e foram produzidas plântulas normais de todos os cruzamentos (Tab. 4). Este resultado mostra compatibilidade interespecífica existente entre as jabuticabeiras, em todos os experimentos realizados.

As sementes oriundas dos tratamentos manipulativos germinaram normalmente, evidenciando sucesso na formação de híbridos. Porém, a não formação de frutos e a formação de frutos não desenvolvidos completamente podem ser resultado de certo grau de incompatibilidade genética ou barreiras pós-zigóticas parciais entre as espécies.

Entretanto, para assegurar a viabilidade de um híbrido, um parâmetro importante é a sua fertilidade, uma vez que diferenças no número cromossômico ou a falta de homologia entre os cromossomos de diferentes espécies podem acarretar em esterilidade. Os estudos citogenéticos em 
Tabela 1. Genótipos analisados através dos marcadores RAPD, sendo 66 amostras de jabuticabeiras e uma amostra de jambeiro vermelho.

\begin{tabular}{|c|c|c|c|}
\hline Número & Identificação & Nome comum & Nome científico \\
\hline 1 & $\mathrm{~A} 1$ & Sabarazinha & Myrciaria jaboticaba \\
\hline 2 & A2 & Sabarazinha & Myrciaria jaboticaba \\
\hline 3 & A3 & Pingo de mel & Myrciaria jaboticaba \\
\hline 4 & A4 & Coroada & Myrciaria cauliflora \\
\hline 5 & A5 & Coroada miúda & Myrciaria cauliflora \\
\hline 6 & A6 & Ponhema & Myrciaria cauliflora "ponhema" \\
\hline 7 & A7 & Sabará amarga & Myrciaria cauliflora \\
\hline 8 & A8 & Coroada miúda & Myrciaria coronata \\
\hline 9 & A9a & - & Myrciaria cauliflora \\
\hline 10 & $\mathrm{~A} 9 \mathrm{~b}$ & Pintada & Myrciaria jaboticaba \\
\hline 11 & A10a & - & Myrciaria sp.1 \\
\hline 12 & A11a & Sabará de penca & Myrciaria sp. x Myrciaria jaboticaba \\
\hline 13 & A11b & - & Myrciaria sp.2 \\
\hline 14 & A12 & - & Myrciaria cauliflora \\
\hline 15 & A13 & - & Myrciaria sp.3 \\
\hline 16 & A14 & Sabará de penca & Myrciaria sp. x Myrciaria jaboticaba \\
\hline 17 & A15 & Jabuticaba jambo & Myrciaria jaboticaba \\
\hline 18 & A16 & Sabará & Myrciaria jaboticaba \\
\hline 19 & A17 & Vermelha & Myrciaria sp. 7 \\
\hline 20 & B1 & Pingo de mel & Myrciaria jaboticaba \\
\hline 21 & B2 & Pingo de mel & Myrciaria jaboticaba \\
\hline 22 & B3 & De penca & Myrciaria trunciflora \\
\hline 23 & B5 & Sabarazinha & Myrciaria jaboticaba \\
\hline 24 & B6 & Coroada & Myrciaria cauliflora \\
\hline 25 & B7 & Coroada & Myrciaria cauliflora \\
\hline 26 & B8 & Coroada & Myrciaria cauliflora \\
\hline 27 & B9 & - & M. jaboticaba x M. coronata \\
\hline 28 & B10 & Coroada & Myrciaria sp.4 \\
\hline 29 & B11a & Coroada & Myrciaria cauliflora \\
\hline 30 & B11b & Coroada & Myrciaria coronata \\
\hline 31 & B12 & Coroada & Myrciaria coronata \\
\hline 32 & B13 & Coroada casca fina & Myrciaria coronata \\
\hline 33 & B14 & De penca & Myrciaria trunciflora \\
\hline 34 & B15 & Coroada & Myrciaria coronata \\
\hline 35 & B16 & Coroada & Myrciaria coronata \\
\hline 36 & B17 & De penca & Myrciaria trunciflora \\
\hline 37 & $\mathrm{C} 1$ & Sabará de penca & Myrciaria jaboticaba \\
\hline 38 & $\mathrm{C} 2$ & Bicuda & Myrciaria sp.5 \\
\hline 39 & $\mathrm{C} 4$ & Jabuticaba jambo & Myrciaria jaboticaba \\
\hline 40 & C5 & Coroada & Myrciaria coronata \\
\hline 41 & $\mathrm{C} 6$ & Sabará & Myrciaria jaboticaba \\
\hline 42 & $\mathrm{C} 8$ & Coroada & Myrciaria cauliflora \\
\hline 43 & C9 & Coroada & Myrciaria cauliflora \\
\hline 44 & $\mathrm{C} 10$ & Coroada & Myrciaria cauliflora \\
\hline
\end{tabular}


Table 1. Continuação.

\begin{tabular}{|c|c|c|c|}
\hline Número & Identificação & Nome comum & Nome científico \\
\hline 45 & $\mathrm{C} 11$ & Coroada & Myrciaria cauliflora \\
\hline 46 & $\mathrm{C} 12$ & De penca Ipuiúna & Myrciaria trunciflora \\
\hline 47 & $\mathrm{C} 13$ & De penca & Myrciaria trunciflora \\
\hline 48 & $\mathrm{C} 14$ & Coroada & Myrciaria cauliflora \\
\hline 49 & $\mathrm{C} 15$ & - & M. jaboticaba $\mathrm{x}$ M. cauliflora \\
\hline 50 & $\mathrm{C} 16$ & Branca & Myrciaria aureana \\
\hline 51 & D2 & Coroada & Myrciaria cauliflora \\
\hline 52 & D3 & Vermelha de penca & Myrciaria trunciflora "vermelha" \\
\hline 53 & D5 & Coroada & Myrciaria sp.6 \\
\hline 54 & D6 & Coroada & Myrciaria sp.6 \\
\hline 55 & D7 & De penca & Myrciaria trunciflora \\
\hline 56 & D8 & Coroada & Myrciaria cauliflora \\
\hline 57 & D9 & De penca & Myrciaria trunciflora \\
\hline 58 & D10 & Sabará de penca & Myrciaria jaboticaba \\
\hline 59 & D11 & Coroada & Myrciaria coronata \\
\hline 60 & D12 & Bicuda & Myrciaria sp. 5 \\
\hline 61 & D13 & Coroada & Myrciaria coronata \\
\hline 62 & D14 & - & Myrciaria sp. x M. trunciflora \\
\hline 63 & D15 & Coroada café & Myrciaria coronata \\
\hline 64 & D16 & Coroada & Myrciaria coronata \\
\hline 65 & D17 & Bicuda & Myrciaria sp.5 \\
\hline 66 & D18 & De penca & Myrciaria trunciflora \\
\hline 67 & $\mathrm{Jb}$ & Jambo Vermelho & Syzygium malaccense \\
\hline
\end{tabular}

Tabela 2. Percentual de frutificação oriunda das polinizações experimentais de apomixia, autopolinização espontânea, autopolinização manual e polinização aberta natural em quatro espécies de Myrciaria (jabuticabeiras) em Coqueiral, Minas Gerais.

\begin{tabular}{lccccccc}
\hline Espécies & Apomixia & $\mathrm{N}$ & $\begin{array}{c}\text { Autopolinização } \\
\text { espontânea }\end{array}$ & $\mathrm{N}$ & $\begin{array}{c}\text { Autopolinização } \\
\text { manual }\end{array}$ & $\mathrm{N}$ & $\begin{array}{c}\text { Polinização } \\
\text { aberta }\end{array}$ \\
\hline M. coronata & $0 \%$ & 12 & $17 \%$ & 41 & $33 \%$ & 6 & - \\
M. jaboticaba & $0 \%$ & 8 & $45 \%$ & 101 & - & - & $44 \%$ \\
M. trunciflora & $0 \%$ & 19 & $8 \%$ & 41 & - & - & $32 \%$ \\
M. cauliflora & $0 \%$ & 10 & $8,6 \%$ & 58 & - & - & $38,5 \%$ \\
\hline
\end{tabular}

$\mathrm{N}$ - número de indivíduos (flores) amostrados.

Tabela 3. Percentual de frutificação oriunda das polinizações experimentais interespecíficas entre espécies de Myrciaria em Coqueiral, Minas Gerais.

\begin{tabular}{|c|c|c|c|c|}
\hline \multirow[t]{2}{*}{ Cruzamentos realizados } & \multicolumn{3}{|c|}{ Resultados } & \multirow[b]{2}{*}{$\mathrm{N}$} \\
\hline & $\begin{array}{c}\mathrm{N}^{\circ} \text { frutos } \\
\text { desenvolvidos }\end{array}$ & $\begin{array}{c}\text { Frutos } \\
\text { abortados }\end{array}$ & $\begin{array}{c}\text { Não houve } \\
\text { formação de frutos }\end{array}$ & \\
\hline M. coronata $\odot$ x M. jaboticaba ${ }^{\lambda}$ & $8(22 \%)$ & $14(39 \%)$ & $14(39 \%)$ & 36 \\
\hline M. jaboticaba + x M. coronata ${ }^{\lambda}$ & $4(27 \%)$ & $0(0 \%)$ & $11(73 \%)$ & 15 \\
\hline M. trunciflora ${ }^{\circ}$ x M. cauliflora $\widehat{\partial}$ & $8(27 \%)$ & $7(23 \%)$ & $15(50 \%)$ & 30 \\
\hline 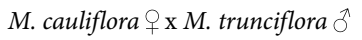 & $5(23 \%)$ & $2(9 \%)$ & $15(68 \%)$ & 22 \\
\hline
\end{tabular}

$\mathrm{N}$ - número de indivíduos (flores) amostrados. 


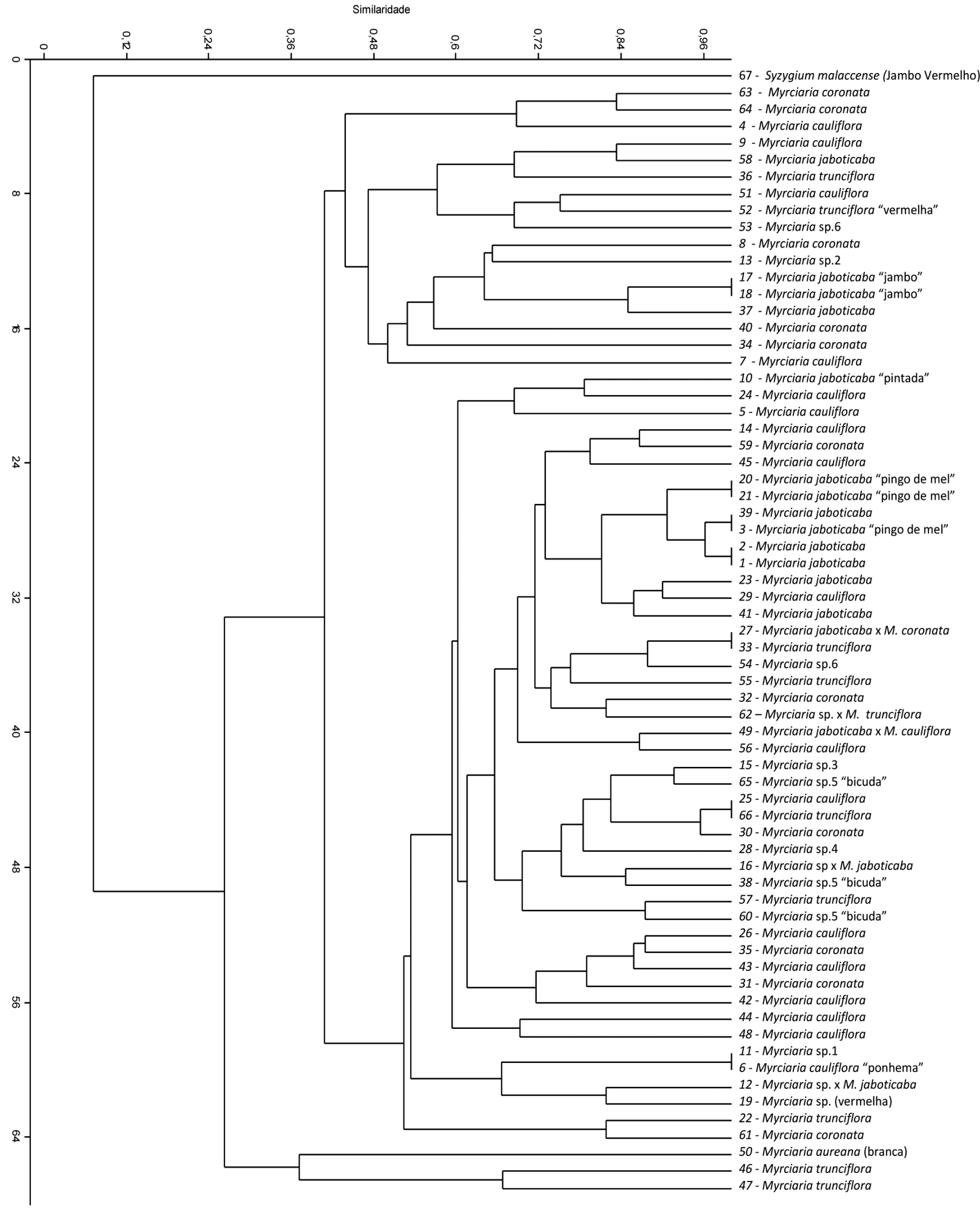

Figura 1. Dendrograma de similaridade genética, obtido através do coeficiente de Jaccard, de 66 genótipos de jabuticabeiras e 01 jambeiro vermelho. 
Tabela 4. Percentual de germinação das sementes resultantes das polinizações experimentais interespecíficas em Myrciaria.

\begin{tabular}{|c|c|c|}
\hline Cruzamento & Germinação & $\mathrm{N}$ \\
\hline M. coronata $\bigcirc$ x M. jaboticaba $\widehat{O}$ & $25 \%$ & 12 \\
\hline 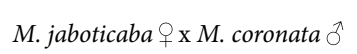 & $100 \%$ & 6 \\
\hline M. trunciflora 早 M. cauliflora $\partial$ & $92 \%$ & 13 \\
\hline M. cauliflora $\bigcirc$ × M. trunciflora $\partial$ & $63 \%$ & 11 \\
\hline
\end{tabular}

$\mathrm{N}$ - número de indivíduos (flores) amostrados.

Myrciaria são escassos. Em trabalho de caracterização citogenética, Silveira et al. (2006) encontraram números divergentes para a quantidade de cromossomos em duas espécies de jabuticabeira. Em Myrciaria cauliflora foi encontrado 2n $=22$ e em Myrciaria trunciflora, $2 \mathrm{n}=48$. Em análise de 19 espécies de três gêneros de Mytaceae, incluindo as espécies Myrciaria delicatula, M. dubia, M. tenella, Myrciaria sp., Plinia cauliflora $(=$ M. cauliflora) e Plinia glomerata, o número básico da família foi $\mathrm{x}=11$ e todas as espécies de Myciaria e Plinia foram diplóides, embora poliplóides tenham sido encontrados no gênero Eugenia (Costa 2004). Assim, o resultado encontrado por Silveira et al. (2006) para Myrciaria trunciflora $(2 \mathrm{n}=48)$ foi considerado surpreendente. Apesar deste relato, os experimentos de polinização cruzada entre $M$. trunciflora e M. cauliflora produziram frutos normais com sementes viáveis e os embriões devem ter sido obtidos pela via sexual uma vez que nossos resultados rejeitam a possibilidade de apomixia.

Ainda que mecanismos de isolamento pós-zigóticos, tais como esterilidade ou degenerescência do híbrido, sejam confirmados no futuro, a compatibilidade de cruzamentos mostrada neste trabalho remete a uma possível pequena diferenciação genética e o isolamento seria devido principalmente ao isolamento geográfico. No entanto, existem espécies ocorrendo em simpatria na natureza e, também, em cultivos. Conforme relatado por M. Lacerda (informação pessoal), Myrciaria jaboticaba e M. coronata ocorrem em simpatria no Vale do Rio Doce, Minas Gerais. Neste trabalho, estas espécies foram hibridizadas e houve formação de frutos normais. Dessa forma, podemos inferir que a inexistência de isolamento pré- ou pós-zigóticos entre eles pode levar a produção de híbridos em áreas de ocorrência natural. Algumas populações são parcialmente diferenciadas, pois possuem algum tipo de isolamento, sendo ainda de difícil classificação (Frankham et al. 2008).

\section{Marcadores RAPD}

Para a análise dos marcadores moleculares foram testados 12 primers, porém, apenas oito proporcionaram confiabilidade (AL03, AL04, AL05, AL07, AL13, AL15, AX05 E AX06) e foram analisados, sendo que os quatro primers que não apresentaram eficiência na amplificação, não puderam ser considerados. Os oito primers citados geraram 37 bandas polimórficas e apenas as bandas mais intensas foram consideradas. Os subgrupos formados apresentaram divergência genética em torno de 50\%.

A diferenciação genética entre as espécies de jabuticabeiras nos poucos estudos realizados com o gênero, todos utilizando o marcador de RAPD, mostraram pouca diferenciação entre as espécies, uma vez que formaram clados mal resolvidos (Pereira 2003), evidenciando uma base genética comum entre todas as jabuticabeiras (Costa 2003).

Neste trabalho, da mesma forma encontramos uma clara falta de definição dos grupos taxonômicos. Os agrupamentos de diferentes níveis de similaridade genética entre os táxons estudados, não correspondem às classificações taxonômicas e analisando o dendrograma obtido (Fig. 1), pode-se notar a grande divergência genética entre os táxons, em torno de $50 \%$.

Isto pode ser reflexo da dificuldade de classificação do gênero Myrciaria, e indica uma necessidade de definição das características morfológicas efetivamente discriminantes para as espécies. Com base nos resultados obtidos, podemos sugerir que os principais caracteres de valor taxonômico são polimórficos dentro do gênero.

Todos os cruzamentos interespecíficos tiveram resultados de produção de frutos em torno de $25 \%$ e isto sugere que o grau de divergência genética não influenciou a capacidade de cruzamento.

Neste estudo, foram realizadas análises de DNA de 66 plantas de 18 táxons originadas de vários estados brasileiros, mostrando assim, a grande diferença morfológica e diversidade genética desta coleção. A capacidade de intercruzamento evidenciada neste trabalho pode ser explorada no melhoramento genético da espécie, visando a transferência de caracteres de interesse presentes em algum genótipo agronomicamente superior.

\section{Agradecimentos}

A Marco Lacerda e Marcos Sobral, pelo auxílio na identificação das espécies; a Maria Cecília de L. e Sá de Alencar Rocha, Camila M. Pigozzo e Gleiciani Bürger Patricio pela grande ajuda durante o desenvolvimento dos trabalhos; a João Bosco dos Santos (UFLA), pela disponibilização de materiais e equipamentos do laboratório de genética molecular; a Márcia Ribeiro pela ajuda na extração do DNA; ao CNPq pelo apoio financeiro e a bolsa de produtividade em pesquisa a Bladina Felipe Viana.

\section{Referências bibliográficas}

Barroso, G.M. 1991. Sistemática de Angiospermas do Brasil. v. 2. Viçosa, Universidade Federal de Viçosa.

Bawa, K.S. 1974. Breeding systems of tree species of a lowland tropical community. Evolution 28: 85-92.

Brasil. 1992. Ministério da Agricultura e Reforma Agrária. Normas Climatológicas: 1961-1990.

Cansian, R.L. 2003. Variabilidade genética de compostos voláteis e semivoláteis em populações nativas de Ilex paraguariensis (St. Hill) do Brasil, visando a conservação da espécie. Tese de Doutorado. Universidade de São Carlos, São Carlos. 
Costa, I.R. 2004. Estudos cromossômicos em espécies de Myrtaceae Juss. no sudeste do Brasil. Dissertação de Mestrado, Unicamp, Campinas, SP.

Costa, J.R.V. da. 2003. Uso de marcadores morfológicos e moleculares do tipo RAPD em jabuticabeiras (Myrciaria spp.). Dissertação de Mestrado. Universidade Estadual Paulista "Julio de Mesquita Filho", Jaboticabal, SP.

Dafni, A.; Kevan, P.G. \& Husband, B.C. (Eds.). 2005. Practical Pollination Ecology. Cambridge: Cambridge University Press. 590p.

Donadio, L.C. 2000. Jaboticaba [Myrciaria jaboticaba (Vell.) Berg]. Jaboticabal: FUNEP, 55p

Frankham, R.; Ballou, J.D. \& Briscoe, D.A. 2008. Fundamentos de Genética da Conservação. Sociedade Brasileira de Genética: Editora SBG, 262 p.

Hammer, Ø; Harper, D.A.T. \& Ryan, P.D. 2001. Past: Paleontological Statistical software package for education and data analysis. Palaentologia Electronica 4(1): 9. Disponível em: http://folk.uio.no/ohammer/past/.

Kearns, C.A. \& Inouye, D. W. 1993. Techniques for Pollination Biologists. Colorado University Press, Niewot, Colorado.

Landrum, L.R. \& Kawasaki, M.L. 1997. The genera of Myrtaceae in Brazil: an illustrated synoptic treatment and identification keys. Brittonia 49(4): 508-536

Lodhi, M.A.; Ye, G.N.; Weeden, N.F. \& Reisch, B.I. 1994. A simple and efficient method for DNA extraction from grapevine cultivars and Vitis species. Plant Molecular Biology Reporter 12(1): 6-13.

Lorenzi, H.; Backer, L.; Lacerda, M. \& Sartori, S. 2006. Frutas Brasileiras e Exóticas Cultivadas. São Paulo, Instituto Plantarum de Estudos da Flora.

Ludghdha, E.N. \& Proença, C. 1996. A survey of the reproductive biology of the Myrtoideae (Myrtaceae). Annals of the Missouri Botanical Garden 83: 480-503.
Marchiori, J.N.C. \& Sobral, M. 1997. Dendrologia das angiospermas Myrtales. Santa Maria, Editora da UFSM.

Maués, M.M. \& Couturier, G. 2002. Biologia floral e fenologia reprodutiva de camu-camu (Myrciaria dubia (H.B.K.) McVaugh, Myrtaceae) no Estado do Pará, Brasil. Revista Brasileira de Botânica 25(4): 441-448.

Morton, J. 1987. Jaboticabas. Pp. 371-374. In: Fruits of warm climates. Miami, Julia F. Morton.

Pereira, M. 2003. Propagação via estacas apicais, caracterização morfológica e molecular de jabuticabeiras (Myrciaria spp.). Tese de Doutorado. Piracicaba.

Proença, C.E.B. \& Gibbs, P.E. 1994. Reproductive biology of eight sympatric Myrtaceae from Central Brazil. New Phytologist 126: 343-354.

Romagnolo, M.B. \& Souza, M.C. 2004. Os gêneros Calycorectes O. Berg, Hexachlamys O. Berg, Myrcianthes O. Berg, Myrciaria O. Berg e Plinia L. (Myrtaceae) na planície alagável do alto rio Paraná, Brasil. Acta Botanica Brasilica 18(3): 613-627.

Santos, K.L. dos; Lenzi, M.; Caprestano, C.A.; Dantas, A.C. de M.; Ducroquet, J.P.H.J.; Nodari, R.O.; Orth, A.I. \& Guerra, M.P. 2007. Evidência da atuação do sistema e auto-incompatibilidade tardia em Acca Sellowiana (Berg) Burret. (Myrtaceae). Revista Brasileira de Fruticultura 29: 120-123

Silveira, F.T.; Ortolani, F.A.; Mataqueiro, M.F. \& Moro, J. R. 2006. Caracterização citogenética em duas espécies do gênero Myrciaria. Revista de Biologia e Ciências da Terra 6(2): 327-333.

Williams, J.G.K.; Kubelik, A.R.; Livak, K.J.; Rafalski, J.A. \& Tingey, S.V. 1990. DNA polymorphism amplified by arbitrary primers are useful as genetic markers. Nucleic Acids Research 18: 6531-6535.

Zucchi, M.I. 2002. Análise da estrutura genética de Eugenia dysenterica DC utilizando marcadores RAPD e SSR. Tese de doutorado. Escola Superior de Agricultura "Luiz de Queiroz". Piracicaba, SP. 